\title{
JOURNAL.RU
}

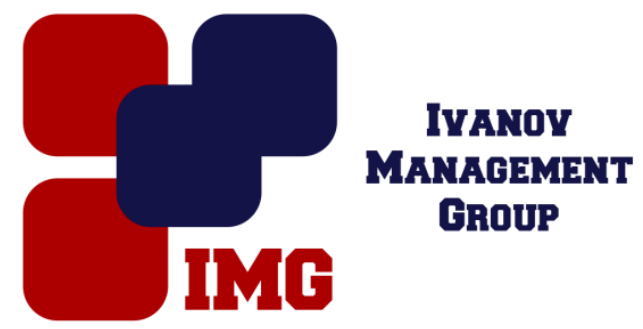

Николаев Е. Д.

Московский архитектурный институт (Государственная академия) Москва, Россия

doi: $10.18411 / 1 \mathrm{j}-31-07-2017-16$

idsp 000001:1j-31-07-2017-16

\section{Реконструкция и перспективное развитие центральной части города Десногорск}

\section{Аннотация.}

Ткань города.

Характерными признаками городского каркаса являются движение, многофункциональная насыщенность и высокая интенсивность освоения пространства.

Ткань города - это основной материально-пространственный субстрат городского организма, где локализована человеческая жизнь и где пространство всегда соразмерно человеческому масштабу.

Ткань города - это материализованная основа городской, или урбанизированной среды.

Лицо города - его иеентр

Вот как писал о роли центра города один из виднейших советских архитекторов-градостроителей В. Н. Семенов: «Центр держит композицию всего города, придает ей тон и масштабность, это ведущий ансамбль, дающий выразительность и лицо всему городу и органически со всем городом связанный».

Рекреация(от лат. Recreatio - восстановление).

Восстановление сил, отдых, проведение людьми своего свободного от работы времени; место отдыха.

Рекреационная зона

Специально выделяемая территория в пригородной местности или в городе, предназначенная для организации мест отдыха населения и включающие в себя 
парки, сады, городские леса, лесопарки, пляжи, особо охраняемые природные территории и природные объекты.

Ключевые слова: Ткань города, лицо города, рекреационный путь, общественный центр,общественное пространство.

\section{Введение. Постановка проблемы}

Термин «общественное пространство» применяется к конкретным городским местам, таким как площадь, улица или парк, где происходит городская общественная жизнь. В современных условиях высокоурбанизированная городская среда и общественное пространство уже не может рассматриваться только в контексте площади или парка, а представляет собой развивающуюся сеть на всем городском поле.

Город Десногорск не соответствует эстетическим и техническим требованиям современного мира. Наблюдается неорганизованность и запущенность городской ткани: отсутствие общественного ядра, отсутствиечеткого маршрута передвижения по общественному пространству, отсутствие фасада города (лицо города).

Население не может удовлетворить свои запросы в существующей городской среде,наблюдается недостаток общественных структур для полноценной ежедневной жизни.

В центральной части города сохранилась свободная площадка,которую можно использовать для формирования современной городской среды.

\section{Анализ градостроительной ситуации}

Десногорск - город в Смоленской области. Строился город для обеспечения функционирования Смоленской АЭС. Расположен на юго-востоке Смоленской области, на правом берегу реки Десны, образующей здесь Десногорское водохранилище площадью 42 кв. км.

\section{Транспорт}

В городе имеются два автотранспортных предприятия. Город Десногорск связан регулярными междугородными автобусными рейсами с г. Москва, г. Брянск, г. Смоленск и др. По городу курсируют автобусы атомной станции, которые перевозят сотрудников и жителей по городу.

\section{Демографические условия}

В структуре постоянного населения города основную долю занимают граждане трудоспособного возраста $(73,1 \%)$. Доля населения старше трудоспособного возраста составляет около $12 \%$.

В городе есть три возрастных группы людей, которые имеют различные 
«возрастные» потребности, сильно отличающиеся друг от друга и для которых требуются индивидуальные пространства и мероприятия.

\section{Социально-экономические условия}

Основу экономики г. Десногорска составляет промышленность $-95,5 \%$.

Основную долю промышленного производства г. Десногорска занимает «производство и распределение электроэнергии, газа и воды», представленное филиалом ОАО «Концерн Росэнергоатом» «Смоленская атомная станция».

АЭС расположена на юге Смоленской области в 3 км от города Десногорск.

Практически каждая десногорская семья, так или иначе, связана со Смоленской АЭС, каждый пятый взрослый житель Десногорска работает на АЭС.

\section{Градостроительная концепция.}

Социально-экономическое развитие города зависит от устойчивой и стабильной работы градообразующего предприятия.

Во время обновления реактора Смоленской АЭС, освободились на время от постоянной работы 2000 человек, которым требуется альтернативная работа.

Основная цель - создание альтернативных рабочих мест атомной энергетике.

Соседство Десногорска с городами с развитым производством и наличием свободных рабочих мест, делает возможным наладить рабочий транзит между ними.

\section{Развитие туристического потока в городе:}

1. модернизация и рекламная программа круглогодичного рыболовного спорта.

2. модернизация и рекламная программа спорткомплекса по альпинизму.

3. использование водных ресурсов.

Генеральным планом предусматривается проведение целого ряда мероприятий по развитию транспортной схемы, включая железнодорожное сообщение и строительство второй автодороги для выхода на федеральную трасcу.

\section{Социальный-пространственный анализ городской территории}




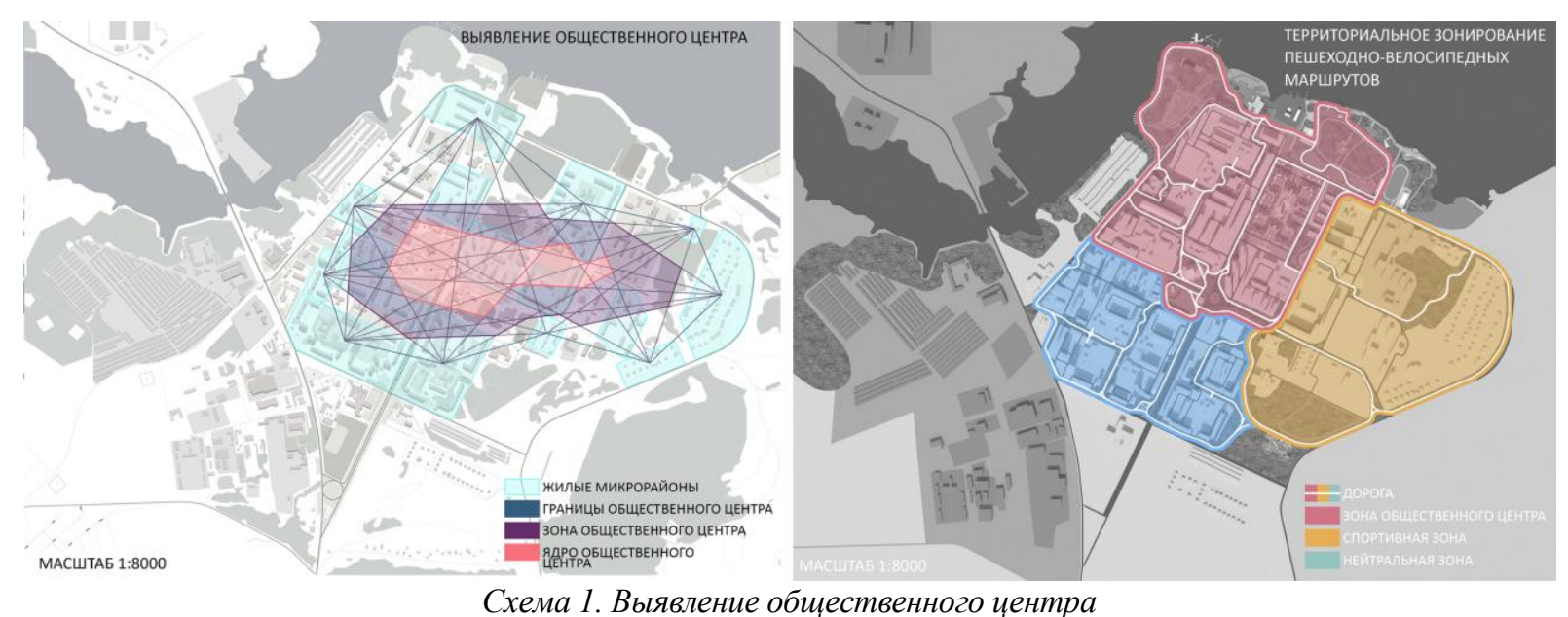

Схема 2. Территориальное зонирование пешеходно-велосипедных маршрутов.

\section{Развитие городской среды.}

Формирование пешеходного и велосипедного пути через весь город для связки всех социальных пространств.

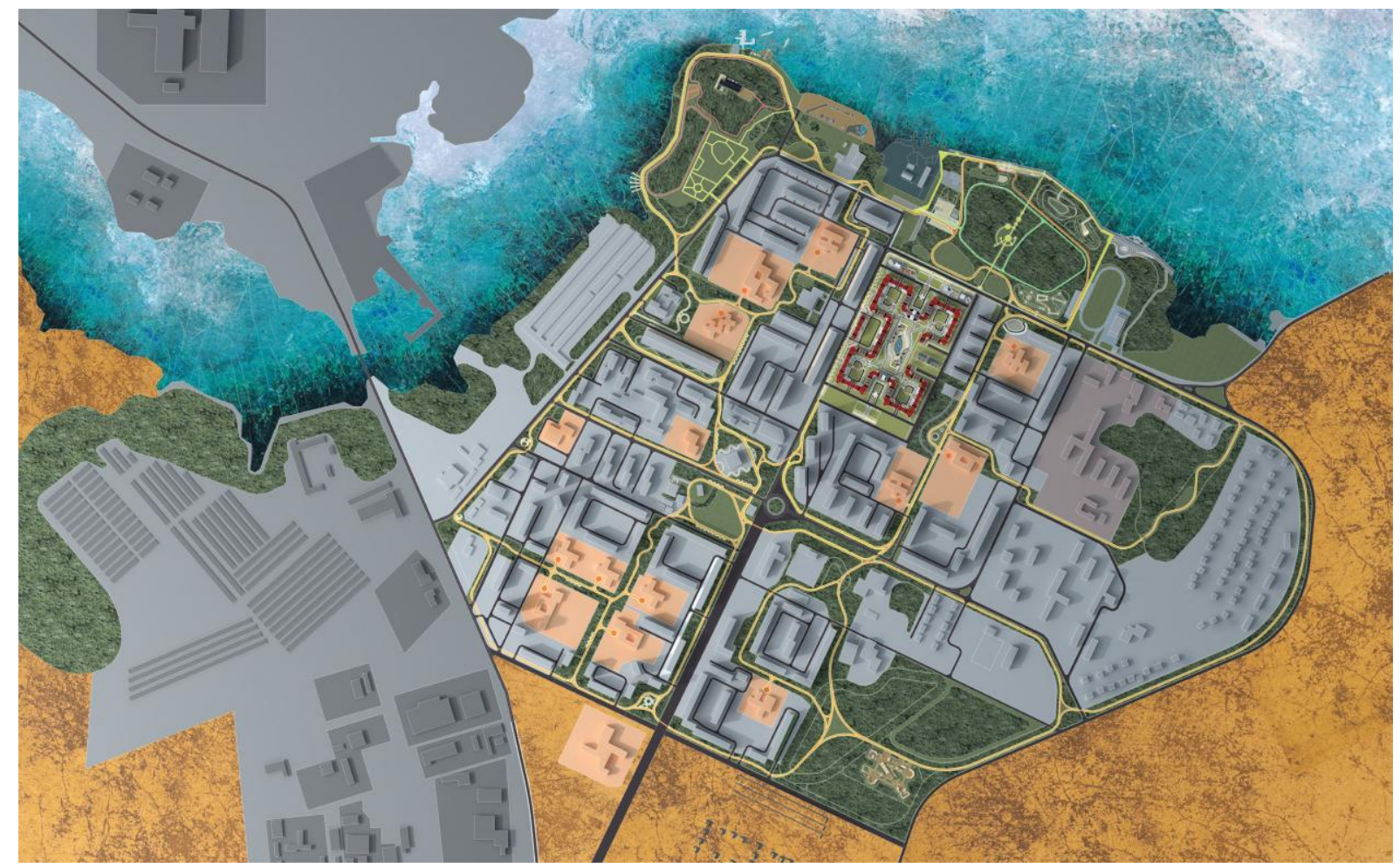

Схема 3.Разработка пешеходного и велосипедного кольца по городу, для связки всех сочииальных пространств и создания единого рекреационного марирута. 
Развитие городского парка и набережной и связка с городским променадом.

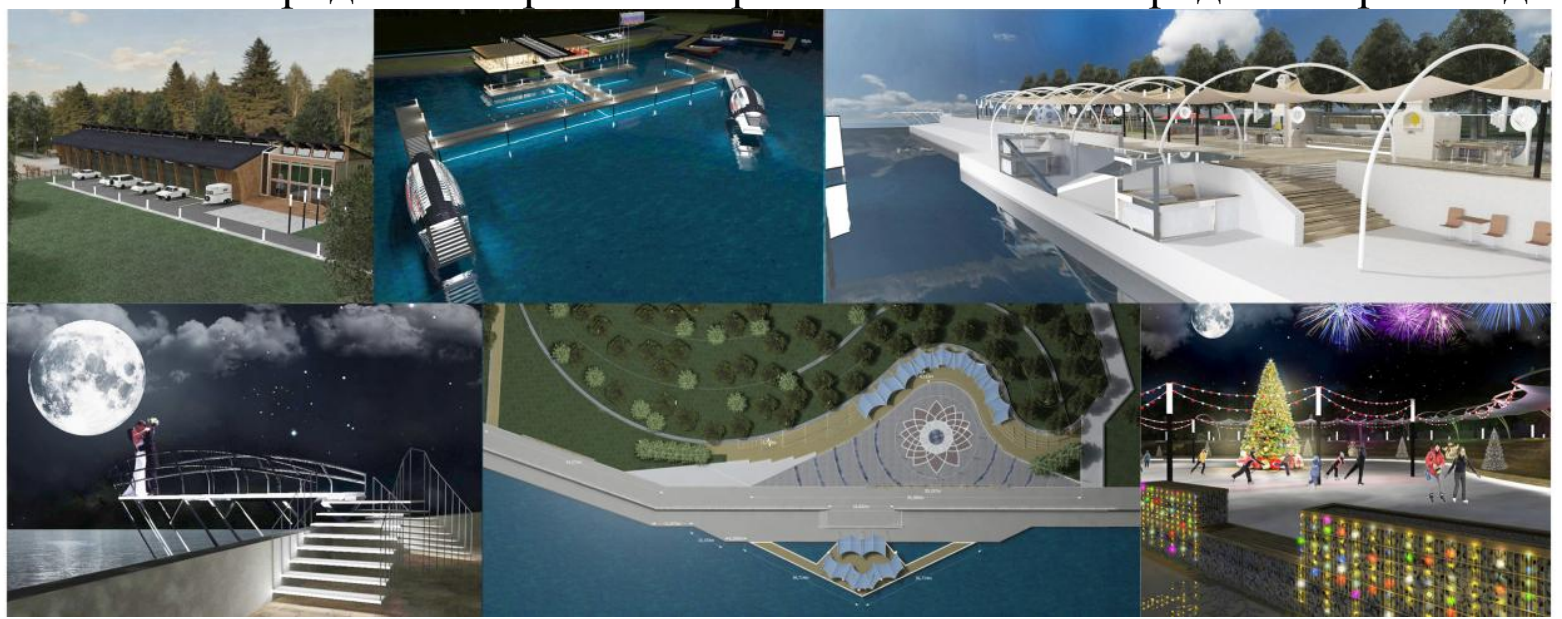

Рис. 1. Конюшня и зооферма. Рис. 2. Яхт-клуб. Рис. 3. Спорт-клуб. Рис. 4. Мост «Титаник». Рис. 5. Амфитеатр. Рис. 6. Каток.

Архитектура градостроительного комплекса.

Создание нового квартала на 2300 человек, для повышения качества жизни.

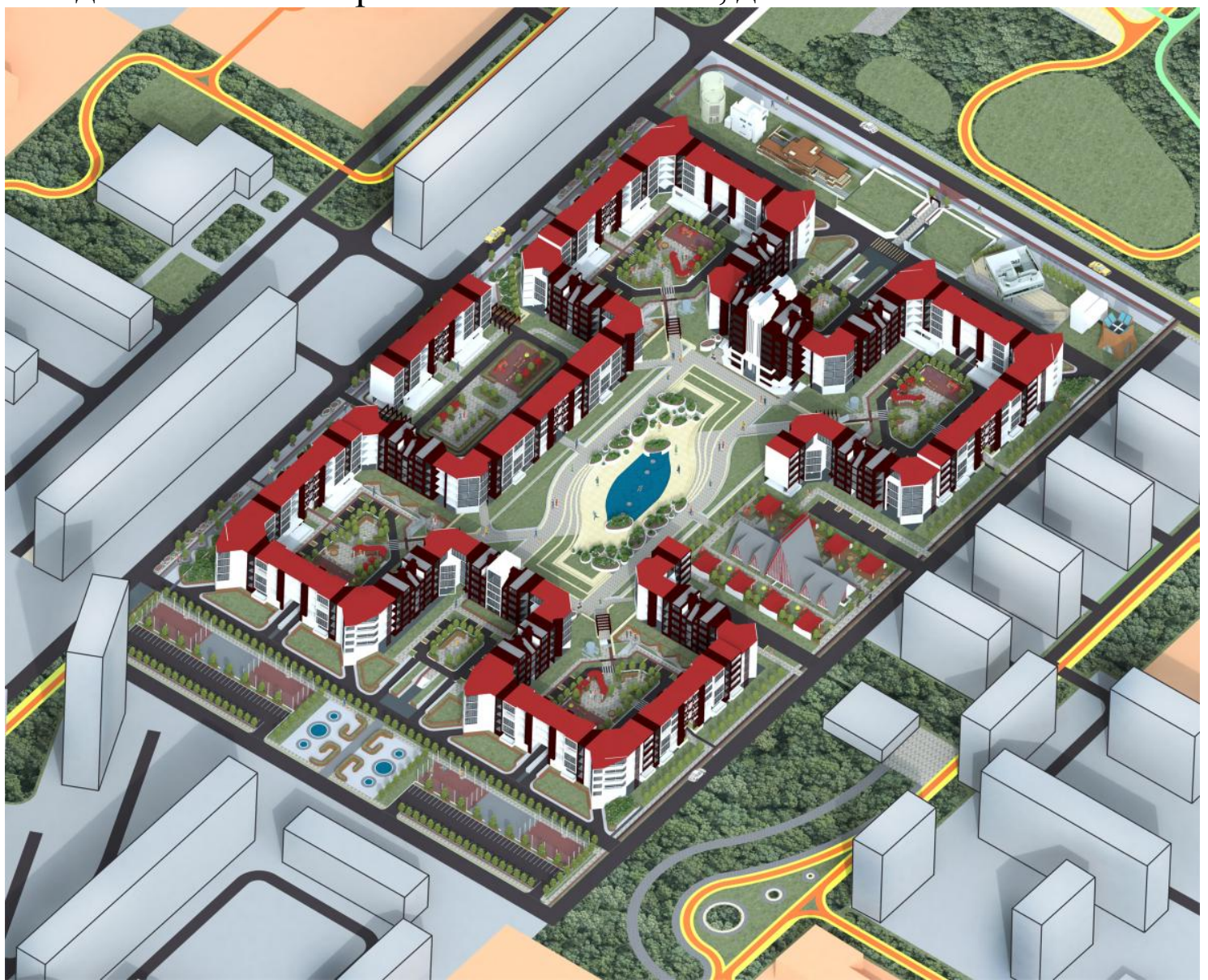

Рис. 3. Квартал на 2300 человек.

\section{Вывод.}

Был разработан социально-демографический прогноз для проектируемого архитектурного и градостроительного объекта. Проанализирован спрос населения 
на новые типы объектов и формы услуг.Определены новые направления развития города. Разработана топологическая модель территории (генеральный план).

Задача градостроительных нововведений - повышение качества городской среды с учетом требований населения и создания целостного планировочного решения.

\section{$* * *$}

1. Семенов В. Н. Основы планировки восстанавливаемых городов//Проблемы современного градостроительства.—№ 1.— 1947.

2. КрашенинниковА.В. МЕЗО-ПРОСТРАНСТВА ГОРОДСКОЙ СРЕДЫ - № 33/15-04 2015.

3. КрашенинниковА.В. МИКРОПРОСТРАНСТВА ГОРОДСКОЙ СРЕДЫ - № 29/14-01 2014.

4. Глазычев В.Л. Урбанистика. 2008 